Original Research Article

\title{
Spatial Distribution of COVID-19 in Honduras at the Early Phase of the Pandemic Using Geographic Information Systems (GIS)
}

Lysien I. Zambrano, ${ }^{1,2,3}$ Manuel Antonio Sierra-Santos, ${ }^{3,4,5,6}$ Homer Mauricio Mejía-Santos, ${ }^{7}$ Elsa Yolanda Palou, ${ }^{3,8}$ Fausto Muñoz-Lara, ${ }^{3,8,9}$ Ivette Lorenzana, ${ }^{3,10}$ Tito Alvarado, ${ }^{3,4}$ Itzel Carolina Fuentes-Barahona, ${ }^{11,12}$ Glaucia Luciano da Veiga, ${ }^{13}$ Ivan Rodriguez-Nuñez, ${ }^{14}$ Víctor Manuel Valladares-Rosa, ${ }^{15}$ Arturo Gerardo Corrales-Alvarez, ${ }^{3,15}$ Kovy Arteaga-Livias, ${ }^{16,17}$ D. Katterine Bonilla-Aldana, ,2,18,19 Alfonso J. Rodríguez-Morales. 2,16,19,20,*

${ }^{1}$ Departamento de Ciencias Fisiológicas y Morfológicas, Facultad de Medicina, Ciencias, Universidad Nacional Autónoma de Honduras (UNAH), Tegucigalpa, Honduras.

${ }^{2}$ Latin American Network of Coronavirus Disease 2019-COVID-19 Research (LANCOVID-19).

Electronic address: https://www.lancovid.org.

${ }^{3}$ Plataforma Todos Contra el COVID-19, Tegucigalpa, Honduras.

${ }^{4}$ Instituto de Enfermedades Infecciosas y Parasitología Antonio Vidal, Tegucigalpa, Honduras.

${ }^{5}$ Facultad de Ciencias Médicas, UNAH, Tegucigalpa DC, Honduras.

${ }^{6}$ Facultad de Ciencias de la Salud, Universidad Tecnológica Centroamericana, Tegucigalpa DC, Honduras.

${ }^{7}$ Unidad de Vigilancia de La Salud (Health Surveillance Unit), Secretaría de Salud, Tegucigalpa, Honduras.

${ }^{8}$ Department of Internal Medicine, Facultad de Ciencias Médicas (FCM), Universidad Nacional Autónoma de Honduras (UNAH), Tegucigalpa DC, Honduras.

${ }^{9}$ Department of Internal Medicine, Hospital Escuela, Tegucigalpa, Honduras 
${ }^{10}$ Escuela de Microbiología, Instituto de Investigaciones en Microbiología, Centro de Investigaciones Genéticas, Universidad Nacional Autónoma de Honduras (UNAH), Tegucigalpa, Honduras.

${ }^{11}$ Facultad de Ciencias Médicas, Universidad Nacional Autónoma de Honduras (UNAH), Tegucigalpa, Honduras.

${ }^{12}$ Departamento de Ginecología y Obstetricia, Hospital Escuela, Tegucigalpa, Honduras.

${ }^{13}$ Departamento Análises Clínicas, Centro Universitario Saude ABC/FMABC, Santo André, Brazil.

${ }^{14}$ Departamento de Kinesiología, Facultad de Medicina, Universidad de Concepción, Chile.

${ }^{15}$ Ingeniería Gerencial, Tegucigalpa, Honduras.

${ }^{16}$ Universidad Científica del Sur, Lima, Peru.

${ }^{17}$ Facultad de Medicina, Universidad Nacional Hermilio Valdizán, Huánuco, Peru.

${ }^{18}$ Incubator in Zoonosis (SIZOO), Biodiversity and Ecosystem Conservation Research Group (BIOECOS), Fundación Universitaria Autónoma de las Américas, Sede Pereira, Pereira, Risaralda, Colombia.

${ }^{19}$ Public Health and Infection Research Group, Faculty of Health Sciences, Universidad Tecnológica de Pereira (UTP), Pereira, Risaralda, Colombia.

${ }^{20}$ Grupo de Investigación Biomedicina, Faculty of Medicine, Fundación Universitaria Autónoma de las Américas, Pereira, Risaralda, Colombia.

*Corresponding author email: arodriguezm@utp.edu.co. Universidad Científica del Sur, Lima, Peru.

Study design: AJRM, Data collection: LIZ, MASS, HMMS,VMVR,AGCA, Data analysis: AJRM, LIZ, DKBA, MASS, HMMS. Writing: All authors. All authors contributed to and approved of the final version submitted.

Competing interests: None of the authors has any conflict of interest to declare.

Words Count: Abstract: 207; Text body: 1897. References: 55. Tables: 2. Figures: 6. 


\section{Abstract}

Background: The epidemic of Coronavirus Disease 2019 (COVID-19) have affected all the regions of the world, nevertheless, in some countries there is a lack of studies on its main clinical and epidemiological features. We analyzed the incidence, incidence rates, and evolution of COVID-19 cases in Honduras from February 18-April 24, 2020.

Methods: Using daily epidemiological data from surveillance about COVID-19 in Honduras, we calculated the rates of incidence (cases/100,000 population), and developed at national, departmental, and municipal levels GIS-based maps.

Results: February 18 - April 24, 2020, a sum of 3,169 suspected COVID-19 cases have been assessed by RT-PCR, 533 (16.8\%) of them were positive, for an incidence rate of 5.73 cases/100,000 pop. The highest peak was reached on March 31 (48 cases). The department with the highest number of cases and incidence rate was Cortes (383 cases, $71.9 \%$ of the total, 21.45 cases/100,000 pop).

Discussion: The pattern and evolution of COVID-19 epidemic in Honduras has been particularly focused in the major urban areas, San Pedro Sula and Tegucigalpa, the capital city. Studies using geographical information systems linked with clinical disease characteristics are necessary to attain accurate epidemiological data for public health systems. Such information is also useful for assessment of the evolution of the pandemic and monitoring interventions.

\section{Keywords}

SARS-CoV-2; COVID-19; geographical information systems (GIS); coronavirus; epidemiology of infectious diseases; public health. 


\section{Background}

Over last few weeks, our world has been affected by a new emerging coronavirus, the Severe Acute Respiratory Syndrome Coronavirus 2 (SARS-CoV-2) (1). This virus is a newly emerging zoonotic agent that appeared in December 2019, or earlier (2), and causes the Coronavirus Disease 2019 (COVID-19) that led to the declaration of an ongoing pandemic, since March 11, $2020(3-6)$

Among the affected regions due to COVID-19 so far, is included Latin America (7-10), where some studies already have reflected the negative impact of this pandemic (11-13). This region has been the epicenter of other emerging epidemics from other viral pathogens since December 2013 (14), such as the case of vector-borne viruses, as chikungunya (CHIKV) (15), Zika (ZIKV) (16) and dengue (DENV) (17).

Now this region is becoming the new epicenter of the COVID-19 pandemic due to uncontrolled situation in Brazil $(18,19)$. Despite this, few is discussed and analyzed in more neglected areas, such as is the case of Central America, where is located Honduras. This country have suitable terms, such as the meteorological factors $(20,21)$, foreign travel, international trade $(22,23)$, spatial sensitivity, that may it be related to introduction and transmission of the SARS-CoV-2 (2428).

As published earlier, in general, there is a lack of reports on viral infectious pathologies in Honduras (29-34), some directly evaluating the Geographic Information Systems (GIS) usefulness to assess the epidemiology of other infectious pathologies, such as CHIKV, ZIKV, and $\operatorname{DENV}(17,34-36)$. 
In the case of COVID-19 in Latin America, there is still a lack of epidemiological studies using GIS to assess the spatial distribution and epidemiology of this pandemic (37-41).

The impact of COVID-19 needs to be evaluated in detail to understand and prepare for public health interventions in the country $(28,41,42)$.

Previous studies using GIS for such assessment have been done as product of the international collaboration with Colombian and Honduran institutions $(24,43)$, e.g. for DENV, CHIKV, and ZIKV $(21,24,37-39,44,45)$. In this setting, this study aimed to estimate incidence rates of COVID-19 in March-April 2020 for Honduras and its departments and municipalities and to develop GISbased epidemiological maps for this coronavirus.

\section{Methods}

Honduras is a Central American country constituted by 18 departments (main administrative level) and 298 municipalities (second administrative level). The Honduran country has meteorological, spatial, and social factors prone for the transmissibility of multiple viral infectious diseases (41), such as temperature, humidity, precipitation, latitude, and altitude, as well as social, cultural, economic and political factors $(24,41)$.

This is an observational, cross-sectional retrospective study. The data were collected from the national system of surveillance, collecting the cases number for all the departments and municipalities in the nation, during February-April 2020 (detailed by days). Data information was comprised derived from the cases, suspected by the clinical definitions, and confirmed by rRTPCR for SARS-CoV-2. Data quality was evaluated. Data evaluated for this analysis was derived 
from a total of 298 primary notification units at the municipalities, gathered at the notification units of the 18 departments, later congregated in the capital district Tegucigalpa (24).

With the 2020 official reference data of the population (Instituto Nacional de Estadisticas, INE), the annual rates of incidence of the corresponding municipalities and departments of Honduras were estimated (cases/100,000 pop), obtaining COVID-19 incidences by municipalities and departments $(24,41)$.

Microsoft Access $\AA$ was used to design the geographical databases to import rates of incidence by municipalities and departments to the GIS software. The Client GIS software Open source used was Kosmo Desktop 3.0 RC1®. The shapefiles of departments (.shp) were associated to the data table database through spatial join operation, to produce digital maps of annual incidence rates by departments and municipalities $(24,39,41,46)$.

\section{Results}

From February 18 to April 23, 2020, a total of 3,169 suspected cases of COVID-19 were investigated, 533 of them (16.8\%), resulting positive by RT-PCR detection of the RNA of the SARS-CoV-2, for a cumulated national incidence rate of 5.73 cases/100,000 pop, varying at departments from 0.0 cases $/ 100,000$ pop (in five departments without cases), to 21.45 cases/100,000 pop (in Cortes). From March 12 to May 24, 2020, a total of 3,950 cases were confirmed (Figure 1), cumulated national incidence rate of 42.45 cases/100,000 pop.

The highest peak was reached on May 23 (273 cases) (Figure 1A). Up to April 23, 22 deaths were confirmed, for a national cumulated national incidence rate of 0.24 deaths $/ 100,000$ pop. But up to May 24, 2020, 180 deaths, 1.93 deaths/100,000 pop (Figure 1B). 
In major cities, Tegucigalpa and San Pedro Sula, more than 2,000 RT-PCR for COVID-19 have been applied (Figure 2A), for rates of over 50 tests/100,000 pop (Figure 2B). In the largest populated departments, such as Cortes and Francisco Morazán, more than 50 tests/100,000 pop were applied in multiple municipalities (Figure 3).

Confirmed cases have been identified especially at Cortes and Francisco Morazán (more than 100 cases in both) (Figure 4A). All the departments except Gracias a Dios, Olancho, El Paraíso, Intibucá, and Ocotepeque, have reported cases (Figure 4B). The highest incidence rates were reached in Cortes and Colon (Figure 4B).

At municipality levels, in the most populated areas, more than 500 tests per municipality have been applied (Figure 5A), with multiple reaching more than 50 tests/100,000 pop (Figure 5B). Nevertheless, multiple municipalities in the country, yet have not applied enough or none tests for COVID-19.

The municipality with the highest number of cases is San Pedro Sula (Figure 6A). At the capital city, Tegucigalpa 58 cases have been confirmed (Figure 6A). Santa Fe, at Colon department, reached 231.71 cases/100,000 pop (Figure 6B), followed by Pimienta (77.36) at Cortes department and San Jose (40.73) at Choluteca department (40.73) (Figure 6B).

From those patients analyzed up to April 22, 2020 (3,169) (Table 1), among confirmed cases there were predominantly males (58\%), 7.3\% younger than 20 years old, and $16.9 \%$ older than 60 years old (Table 1). The highest detection (positivity) was found among those in the group 6069 years old $(31.4 \%)$ (Table 1$)$. 
Among those asymptomatic, 25.3\% were positive for COVID-19 (Table 1). Among confirmed cases, $61.5 \%$ presented cough and $60.2 \%$ fever, among other findings (Table 1 ). From the total COVID-19 cases, $85.7 \%$ presented comorbidities, $10.3 \%$ of the cases with hypertension, $9.8 \%$ with diabetes, among other (Table 1). In this group, 22 died (4.1\%).

Diabetes and hypertension were associated with higher risk of death $(\mathrm{OR}=3.79,95 \% \mathrm{Cl} 1.41$ 10.16, and $\mathrm{OR}=2.71,95 \% \mathrm{Cl} 1.01-7.66)$. All the patients that died have comorbidities, and among those with comorbidities $4.8 \%$ died, compared to those without it where no deaths occurred (Table 2). 


\section{Discussion}

As expected, COVID-19 in Honduras has affected all the age groups, with a higher proportion of deaths among those above 60 years-old and with comorbidities, as other studies have reported in the region and abroad $(6,47,48)$. The GIS-based maps allow to see that the epidemic in the country is affecting mostly those urban populated centers, such as San Pedro Sula, and surrounding municipalities and the capital district, Tegucigalpa, and its neighbouring areas (Figure 6). This is similar to the observed situation in other countries of Latin America, such as Brazil, Colombia, Bolivia and Mexico $(11,13,18,49)$, although so far, no studies using GIS have been published from these countries.

Francisco Morazán and Cortés departments, those with highest population, were the most compromised by COVID-19 till now. Socio-eco-epidemiological characteristics in Honduras are suitable for the entire country sensitive to the spreading of viral infectious diseases such as COVID-19. These conditions make complicated the effective control and containment of this epidemic that is progressing (50). Analyses such as the one presented herein are relevant for understanding future emerging epidemics in the region and the country, as early described (24, 41).

Yet, in Honduras we have to wait to see the impact of seasonal station and environmental conditions on the epidemiology of COVID-19. In the case of seasonal influenza, some studies in the region revealed a proportional association between influenza activity and specific humidity in selected areas from Honduras, Costa Rica and Nicaragua (51).

The use of GIS-epidemiological maps is critical $(24,37,46)$, are of high relevance for any affected country (41). In the case of Central American territories, there is an evident lack of studies 
developing such maps for emerging viral infectious diseases. In Honduras, previous assessments using GIS mapped DENV, CHIKV and ZIKV, were useful for health authorities at national and local levels $(17,34-36)$. In addition to all the above, coinfections between COVID-19 and DENV, should be also considered, as these may overlap in the country, as is being reported in other countries in Latin America (52).

Further studies are essential to understand the epidemiological and medical characteristics of this and other emerging infectious diseases in Honduras. Although this may not provide all the answers, such information is particularly useful for public health evidenced-based decisions (41, 53). Developed maps would provide baseline epidemiological information for the assessment of the differentiated risk related to acquiring such diseases in certain areas (departments and municipalities) of Honduras. Similar recommendations have previously been made for DENV, CHIKV, and other arboviral diseases $(21,24,41)$.

Use of GIS-based epidemiological maps is beneficial for preventative/control strategies in Honduras $(24,37-40,44)$, as well as other countries in Central and South America. These tools, such as GIS-based maps can also be developed and used for making public health decisions about other emerging diseases in Honduras $(41,54)$.

Shortly, other eco-epidemiological evaluations would be done in the country for these emerging diseases, as has been done for vector-borne disease epidemics in the country $(24,41)$. 


\section{Limitations}

Massive scale testing has not yet performed in the country. The RT-PCR SARS-CoV-2 diagnosis is mostly centralized. This scenario is like other nations in the region of Latin America. Besides, there is likely cases under-reporting in some zones as derived from the comparison with precise reporting in some municipalities.

\section{Conclusions}

GIS-based maps are a source of important information for the evaluation of the individuals risk in certain areas allowing detailed prevention advice $(40,41,54)$. Such maps allow integration of prevention and control strategies, as well as public health policies, for joint control of this emerging disease in this and other countries of the region (55). Preparedness in this setting should also consider the potential occurrence of new associated complications of the disease. Finally, considering the emergence of COVID-19 in not previously affected areas, as indicated, in the country would be useful for preventive actions.

\section{Acknowledgments}

Authors would like to give thanks to the Unidad de Vigilancia en Salud, UVS (Unit of Health Surveillance), of the Secretaria de Salud, SESAL (Secretary of Health), Honduras, for contributing with the data. We thank Jackeline Alger, MD, for her support; Eduardo Retes, MD, for his support; Altay de Souza, PhD, the Federal University of Sao Paulo (UNIFESP), for his support.

Funding: Universidad Tecnológica de Pereira, Pereira, Risaralda, Colombia. This study is part of the project "Desarrollo de Mapas Epidemiológicos a través de Sistemas de Información Geográfica para la Caracterización Geográfica de Enfermedades Infecciosas y Tropicales en el Eje Cafetero de Colombia" (Code 5-15-5 [2015-2017]), Universidad Tecnológica de Pereira, Pereira, Risaralda, Colombia. Training on GIS for A. J. Rodriguez-Morales was funded by 
Universidad Tecnológica de Pereira, Pereira, Risaralda, Colombia. The Facultad de Ciencias Médicas (FCM) (2-03-01-01), National Autonomous University of Honduras, Tegucigalpa, MDC, Honduras, supported the publication fees of this article. L.I.Z. was the recipient of the UNAH CU0-041-05-2014/03-2014 scholarship.

Ethical Approval: Not required.

Conflicts of Interest: The authors have no conflict of interest to disclose. All authors provided the ICJME form.

\section{References}

1. R. Sah et al., Complete Genome Sequence of a 2019 Novel Coronavirus (SARS-CoV-2) Strain Isolated in Nepal. Microbiol Resour Announc 9, (2020).

2. A. Deslandes et al., SARS-CoV-2 was already spreading in France in late December 2019. Int J Antimicrob Agents, 106006 (2020).

3. D. K. Bonilla-Aldana, K. Dhama, A. J. Rodriguez-Morales, Revisiting the One Health Approach in the Context of COVID-19: A Look into the Ecology of this Emerging Disease. Adv Anim Vet Sci 8, 234-237 (2020).

4. Rodriguez-Morales AJ et al., Genomic Epidemiology and its importance in the study of the COVID-19 pandemic. Infez Med 28, 139-142 (2020).

5. A. J. Rodriguez-Morales et al., History is repeating itself, a probable zoonotic spillover as a cause of an epidemic: the case of 2019 novel Coronavirus. Infez Med 28, 3-5 (2020).

6. A. J. Rodriguez-Morales et al., Clinical, laboratory and imaging features of COVID-19: A systematic review and meta-analysis. Travel Med Infect Dis, 101623 (2020).

7. Rodriguez-Morales AJ et al., Preparación y control de la enfermedad por coronavirus 2019 (COVID-19) en América Latina. Acta Medica Peruana 37, 3-7 (2020).

8. J. A. Sánchez-Duque, L. R. Arce-Villalobos, A. J. Rodríguez-Morales, Enfermedad por coronavirus 2019 (COVID-19) en América Latina: papel de la atención primaria en la preparación y respuesta. Atención Primaria, (2020).

9. S. Cimerman, A. Chebabo, C. A. d. Cunha, A. J. Rodríguez-Morales, Deep impact of COVID-19 in the healthcare of Latin America: the case of Brazil. The Brazilian Journal of Infectious Diseases, (2020).

10. A. J. Rodriguez-Morales et al., COVID-19 in Latin America: The implications of the first confirmed case in Brazil. Travel Med Infect Dis, 101613 (2020).

11. J. P. Escalera-Antezana et al., Clinical features of the first cases and a cluster of Coronavirus Disease 2019 (COVID-19) in Bolivia imported from Italy and Spain. Travel Med Infect Dis, 101653 (2020).

12. L. I. Zambrano et al., A pregnant woman with COVID-19 in Central America. Travel Med Infect Dis, 101639 (2020).

13. D. A. Diaz-Guio et al., Will the Colombian intensive care units collapse due to the COVID-19 pandemic? Travel Med Infect Dis, 101746 (2020).

14. D. Musso, A. J. Rodriguez-Morales, J. E. Levi, V. M. Cao-Lormeau, D. J. Gubler, Unexpected outbreaks of arbovirus infections: lessons learned from the Pacific and tropical America. Lancet Infect Dis 18, e355-e361 (2018).

15. P. Alfaro-Toloza, D. E. Clouet-Huerta, A. J. Rodriguez-Morales, Chikungunya, the emerging migratory rheumatism. Lancet Infect Dis 15, 510-512 (2015).

16. N. R. Faria et al., Zika virus in the Americas: Early epidemiological and genetic findings. Science 352, 345349 (2016). 
17. L. I. Zambrano, E. Rodriguez, I. A. Espinoza-Salvado, A. J. Rodriguez-Morales, Dengue in Honduras and the Americas: The epidemics are back! Travel Med Infect Dis 31, 101456 (2019).

18. R. K. Singh et al., Prediction of the COVID-19 Pandemic for the Top 15 Affected Countries: Advanced Autoregressive Integrated Moving Average (ARIMA) Model. JMIR Public Health Surveill 6, e19115 (2020).

19. F. A. Diaz-Quijano, A. J. Rodriguez-Morales, E. A. Waldman, Translating transmissibility measures into recommendations for coronavirus prevention. Rev Saude Publica 54, 43 (2020).

20. L. L. Quintero-Herrera et al., Potential impact of climatic variability on the epidemiology of dengue in Risaralda, Colombia, 2010-2011. J Infect Public Health 8, 291-297 (2015).

21. L. I. Zambrano et al., Potential impacts of climate variability on dengue hemorrhagic fever in Honduras, 2010. Tropical biomedicine 29, 499-507 (2012).

22. A. J. Rodriguez-Morales, W. E. Villamil-Gomez, C. Franco-Paredes, The arboviral burden of disease caused by co-circulation and co-infection of dengue, chikungunya and Zika in the Americas. Travel medicine and infectious disease 14, 177-179 (2016).

23. J. A. Sánchez-Duque, A. J. Rodríguez-Morales, A. M. Trujillo, J. A. Cardona-Ospina, W. E. Villamil-Gomez, in Current Topics in Zika. (InTech, 2018).

24. L. I. Zambrano et al., Estimating and mapping the incidence of dengue and chikungunya in Honduras during 2015 using Geographic Information Systems (GIS). Journal of infection and public health 10, 446-456 (2017).

25. A. J. Rodríguez-Morales et al., in Current Topics in Zika. (InTech, 2018).

26. R. Noor, T. Ahmed, Zika virus: Epidemiological study and its association with public health risk. Journal of infection and public health, (2018).

27. N. Wikan, D. R. Smith, Zika virus: history of a newly emerging arbovirus. Lancet Infect Dis 16, e119-e126 (2016).

28. D. S. Younger, Epidemiology of Zika virus. Neurologic clinics 34, 1049-1056 (2016).

29. K. Basile, J. Kok, D. E. Dwyer, Zika virus: what, where from and where to? Pathology 49, 698-706 (2017).

30. D. I. Brissett et al., Zika Virus: Knowledge Assessment of Residents and Health-Care Providers in Roatan, Honduras, following an Outbreak. The American journal of tropical medicine and hygiene 99, 211-215 (2018).

31. T. Brooks et al., Real-Time Evolution of Zika Virus Disease Outbreak, Roatan, Honduras. Emerg Infect Dis 23, 1360-1363 (2017).

32. F. F. Norman et al., Sequential Chikungunya and Zika Virus Infections in a Traveler from Honduras. The American journal of tropical medicine and hygiene 95, 1166-1168 (2016).

33. P. Buekens et al., Zika virus infection in pregnant women in Honduras: study protocol. Reproductive health 13, 82 (2016).

34. L. I. Zambrano et al., Spatial distribution of dengue in Honduras during 2016-2019 using a geographic information systems (GIS)-Dengue epidemic implications for public health and travel medicine. Travel Med Infect Dis, 101517 (2019).

35. L. I. Zambrano et al., Estimating and mapping the incidence of dengue and chikungunya in Honduras during 2015 using Geographic Information Systems (GIS). J Infect Public Health 10, 446-456 (2017).

36. L. I. Zambrano et al., Spatial distribution of Zika in Honduras during 2016-2017 using geographic information systems (GIS) - Implications for public health and travel medicine. Travel Med Infect Dis 31, 101382 (2019).

37. A. J. Rodriguez-Morales et al., Using geographic information system (GIS) to mapping and assess changes in transmission patterns of chikungunya fever in municipalities of the Coffee-Triangle region of Colombia during 2014-2015 outbreak: Implications for travel advice. Travel medicine and infectious disease 14, 62-65 (2016).

38. A. J. Rodriguez-Morales, L. J. Patino-Cadavid, C. O. Lozada-Riascos, W. E. Villamil-Gomez, Mapping Zika in municipalities of one coastal department of Colombia (Sucre) using geographic information systems during the 2015-2016 outbreak: implications for public health and travel advice. International journal of infectious diseases : IJID : official publication of the International Society for Infectious Diseases 48, 70-72 (2016).

39. A. J. Rodriguez-Morales et al., Mapping the ecoepidemiology of Zika virus infection in urban and rural areas of Pereira, Risaralda, Colombia, 2015-2016: Implications for public health and travel medicine. Travel medicine and infectious disease 18, 57-66 (2017).

40. A. J. Rodriguez-Morales et al., Mapping Zika virus disease incidence in Valle del Cauca. Infection 45, $93-102$ (2017).

41. L. I. Zambrano et al., Spatial distribution of Zika in Honduras during 2016-2017 using geographic information systems (GIS) - Implications for public health and travel medicine. Travel medicine and infectious disease, (2019).

42. A. J. Rodríguez-Morales, J. A. Sánchez-Duque, Preparing for next arboviral epidemics in Latin America; who can it be now?-Mayaro, Oropouche, West Nile or Venezuelan Equine Encephalitis viruses. Journal of Preventive Epidemiology 3, (2017).

43. A. J. Rodriguez-Morales et al., Post-chikungunya chronic arthralgia: Results from a retrospective follow-up study of 131 cases in Tolima, Colombia. Travel medicine and infectious disease 14, 58-59 (2016).

44. A. J. Rodriguez-Morales et al., Mapping Zika virus infection using geographical information systems in Tolima, Colombia, 2015-2016. F1000Research 5, 568 (2016). 
45. D. F. Martinez-Pulgarin, W. F. Acevedo-Mendoza, J. A. Cardona-Ospina, A. J. Rodriguez-Morales, A. E. Paniz-Mondolfi, A bibliometric analysis of global Zika research. Travel medicine and infectious disease 14, 55-57 (2016).

46. A. J. Rodriguez-Morales et al., Zika infection GIS-based mapping suggest high transmission activity in the border area of La Guajira, Colombia, a northeastern coast Caribbean department, 2015-2016: Implications for public health, migration and travel. Travel medicine and infectious disease 14, 286-288 (2016).

47. ECDC, "Risk assessment: Outbreak of acute respiratory syndrome associated with a novel coronavirus, China: first local transmission in the EU/EEA - third update," https://www.ecdc.europa.eu/en/publications-data/risk-assessment-outbreak-acute-respiratory-syndromeassociated-novel-1).

48. F. Zhou et al., Clinical course and risk factors for mortality of adult inpatients with COVID-19 in Wuhan, China: a retrospective cohort study. Lancet 395, 1054-1062 (2020).

49. M. Hernandez-Avila, C. M. Alpuche-Aranda, Mexico: Lessons learned from the 2009 pandemic that help us fight COVID-19. Healthc Manage Forum 33, 158-163 (2020).

50. A. Wilder-Smith, C. J. Chiew, V. J. Lee, Can we contain the COVID-19 outbreak with the same measures as for SARS? Lancet Infect Dis, (2020).

51. R. P. Soebiyanto et al., Associations between seasonal influenza and meteorological parameters in Costa Rica, Honduras and Nicaragua. Geospat Health 10, 372 (2015).

52. J.-C. Navarro, J. Arrivillaga-Henríquez, J. Salazar-Loor, A. J. Rodriguez-Morales, COVID-19 and dengue, coepidemics in Ecuador and other countries in Latin America: Pushing strained health care systems over the edge. Travel Medicine and Infectious Disease, 101656 (2020).

53. R. C. Christofferson, Zika Virus Emergence and Expansion: Lessons Learned from Dengue and Chikungunya May Not Provide All the Answers. The American journal of tropical medicine and hygiene 95, 15-18 (2016).

54. L. I. Zambrano, E. Rodriguez, I. A. Espinoza-Salvado, A. J. Rodriguez-Morales, Dengue in Honduras and the Americas: The epidemics are back! Travel medicine and infectious disease, (2019).

55. A. Tami, M. E. Grillet, M. P. Grobusch, Applying geographical information systems (GIS) to arboviral disease surveillance and control: A powerful tool. Travel medicine and infectious disease 14, 9-10 (2016). 
Table 1. Demographic and clinical features of positive and negative patients assessed for COVID-19 in Honduras, March 10-April 22, 2020.

\begin{tabular}{|c|c|c|c|c|c|c|c|c|}
\hline & & \multicolumn{2}{|l|}{$\begin{array}{c}\text { Positive } \\
(n=533)\end{array}$} & \multicolumn{2}{|c|}{$\begin{array}{l}\text { Negative } \\
(n=2636)\end{array}$} & \multirow[b]{2}{*}{ Total } & \multirow[b]{2}{*}{$\%$} & \multirow[b]{2}{*}{$p$} \\
\hline & & $\mathbf{n}$ & $\%$ & $\mathbf{n}$ & $\%$ & & & \\
\hline \multirow[t]{2}{*}{ Sex } & Male & 309 & 58.0 & 1287 & 48.8 & 1596 & 50.4 & $<0.001$ \\
\hline & Female & 224 & 42.0 & 1349 & 51.2 & 1573 & 49.6 & \\
\hline \multirow[t]{11}{*}{ Age group } & $0-4$ & 7 & 4.3 & 156 & 95.7 & 163 & 100.0 & $<0.001$ \\
\hline & $5-9$ & 4 & 4.6 & 83 & 95.4 & 87 & 100.0 & \\
\hline & $10-14$ & 7 & 10.0 & 63 & 90.0 & 70 & 100.0 & \\
\hline & $15-19$ & 21 & 12.7 & 144 & 87.3 & 165 & 100.0 & \\
\hline & $20-29$ & 84 & 12.1 & 612 & 87.9 & 696 & 100.0 & \\
\hline & $30-39$ & 116 & 16.2 & 601 & 83.8 & 717 & 100.0 & \\
\hline & $40-49$ & 115 & 22.6 & 394 & 77.4 & 509 & 100.0 & \\
\hline & $50-59$ & 86 & 21.8 & 308 & 78.2 & 394 & 100.0 & \\
\hline & $60-69$ & 55 & 31.4 & 120 & 68.6 & 175 & 100.0 & \\
\hline & $70-79$ & 26 & 27.4 & 69 & 72.6 & 95 & 100.0 & \\
\hline & $>80$ & 9 & 13.4 & 58 & 86.6 & 67 & 100.0 & \\
\hline \multirow[t]{2}{*}{ Asymptomatic } & Yes & 135 & 25.3 & 2126 & 80.7 & 2261 & 71.3 & $<0.001$ \\
\hline & No & 398 & 74.7 & 510 & 19.3 & 908 & 28.7 & \\
\hline \multirow[t]{4}{*}{ Symptoms } & Cough & 328 & 61.5 & 347 & 13.2 & 675 & 21.3 & $<0.001$ \\
\hline & Fever & 321 & 60.2 & 271 & 10.3 & 592 & 18.7 & \\
\hline & Dyspnea & 186 & 34.9 & 157 & 6.0 & 343 & 10.8 & \\
\hline & Sore throat & 147 & 27.6 & 168 & 6.4 & 315 & 9.9 & \\
\hline \multirow[t]{11}{*}{ Comorbidities } & Yes & 457 & 85.7 & 805 & 30.5 & 1262 & 39.8 & $<0.001$ \\
\hline & No & 76 & 14.3 & 1831 & 69.5 & 1907 & 60.2 & \\
\hline & Hypertension & 55 & 10.3 & 72 & 2.7 & 127 & 4.0 & $<0.001$ \\
\hline & Diabetes & 52 & 9.8 & 47 & 1.8 & 99 & 3.1 & \\
\hline & Cardiovascular disease & 31 & 5.8 & 35 & 1.3 & 66 & 2.1 & \\
\hline & Obesity & 25 & 4.7 & 41 & 1.6 & 66 & 2.1 & \\
\hline & COPD & 21 & 3.9 & 46 & 1.7 & 67 & 2.1 & \\
\hline & Asthma & 14 & 2.6 & 25 & 0.9 & 39 & 1.2 & \\
\hline & Pregnancy & 9 & 1.7 & 21 & 0.8 & 30 & 0.9 & \\
\hline & Alcoholism & 5 & 0.9 & 2 & 0.1 & 7 & 0.2 & \\
\hline & Cancer & 1 & 0.2 & 5 & 0.2 & 6 & 0.2 & \\
\hline \multirow[t]{2}{*}{ Outcome } & Death & 22 & 4.1 & 4 & 0.2 & 26 & 0.8 & $<0.001$ \\
\hline & Survived & 511 & 95.9 & 2632 & 99.8 & 3143 & 99.2 & \\
\hline
\end{tabular}


Table 2. Comparison of selected variables between those patients COVID-19 that died and survived in Honduras, March 10-April 22, 2020.

\begin{tabular}{|c|c|c|c|c|c|c|c|c|}
\hline & & \multicolumn{2}{|c|}{$\begin{array}{c}\text { Dead } \\
(n=22)\end{array}$} & \multicolumn{2}{|c|}{$\begin{array}{c}\text { Survived } \\
(\mathrm{n}=511)\end{array}$} & \multirow[b]{2}{*}{ Total } & & \multirow[b]{2}{*}{$p$} \\
\hline & & $\mathbf{n}$ & $\%$ & $\mathbf{n}$ & $\%$ & & & \\
\hline \multirow[t]{2}{*}{ Sex } & Male & 17 & 77.3 & 292 & 57.1 & 309 & 58.0 & 0.061 \\
\hline & Female & 5 & 22.7 & 219 & 42.9 & 224 & 42.0 & \\
\hline \multirow[t]{11}{*}{ Age group } & $0-4$ & 0 & 0.0 & 7 & 100.0 & 7 & 100.0 & 0.085 \\
\hline & $5-9$ & 0 & 0.0 & 4 & 100.0 & 4 & 100.0 & \\
\hline & $10-14$ & 0 & 0.0 & 7 & 100.0 & 7 & 100.0 & \\
\hline & $15-19$ & 0 & 0.0 & 21 & 100.0 & 21 & 100.0 & \\
\hline & $20-29$ & 0 & 0.0 & 84 & 100.0 & 84 & 100.0 & \\
\hline & $30-39$ & 5 & 4.3 & 111 & 95.7 & 116 & 100.0 & \\
\hline & $40-49$ & 4 & 3.5 & 111 & 96.5 & 115 & 100.0 & \\
\hline & $50-59$ & 3 & 3.5 & 83 & 96.5 & 86 & 100.0 & \\
\hline & $60-69$ & 6 & 10.9 & 49 & 89.1 & 55 & 100.0 & \\
\hline & $70-79$ & 3 & 11.5 & 23 & 88.5 & 26 & 100.0 & \\
\hline & $>80$ & 1 & 11.1 & 8 & 88.9 & 9 & 100.0 & \\
\hline \multirow[t]{11}{*}{ Comorbidities } & Yes & 22 & 4.8 & 435 & 95.2 & 457 & 100.0 & 0.051 \\
\hline & No & 0 & 0.0 & 76 & 100.0 & 76 & 100.0 & \\
\hline & Diabetes & 6 & 27.3 & 46 & 9.0 & 9.8 & 100.0 & 0.005 \\
\hline & Hypertension & 5 & 22.7 & 50 & 9.8 & 10.3 & 100.0 & 0.035 \\
\hline & Cardiovascular disease & 3 & 13.6 & 28 & 5.5 & 5.8 & 100.0 & 0.055 \\
\hline & Obesity & 2 & 9.1 & 23 & 4.5 & 4.7 & 100.0 & 0.106 \\
\hline & COPD & 0 & 0.0 & 21 & 4.1 & 3.9 & 100.0 & 0.078 \\
\hline & Asthma & 0 & 0.0 & 14 & 2.7 & 2.6 & 100.0 & 0.097 \\
\hline & Pregnancy & 0 & 0.0 & 9 & 1.8 & 1.7 & 100.0 & 0.113 \\
\hline & Alcoholism & 0 & 0.0 & 5 & 1.0 & 0.9 & 100.0 & 0.128 \\
\hline & Cancer & 0 & 0.0 & 1 & 0.2 & 0.2 & 100.0 & 0.144 \\
\hline
\end{tabular}


Figure 1. COVID-19 in Honduras, March 12-May 25, 2020. A. Number of confirmed cases and deaths per day. B. Cumulated number of confirmed cases and deaths per day.
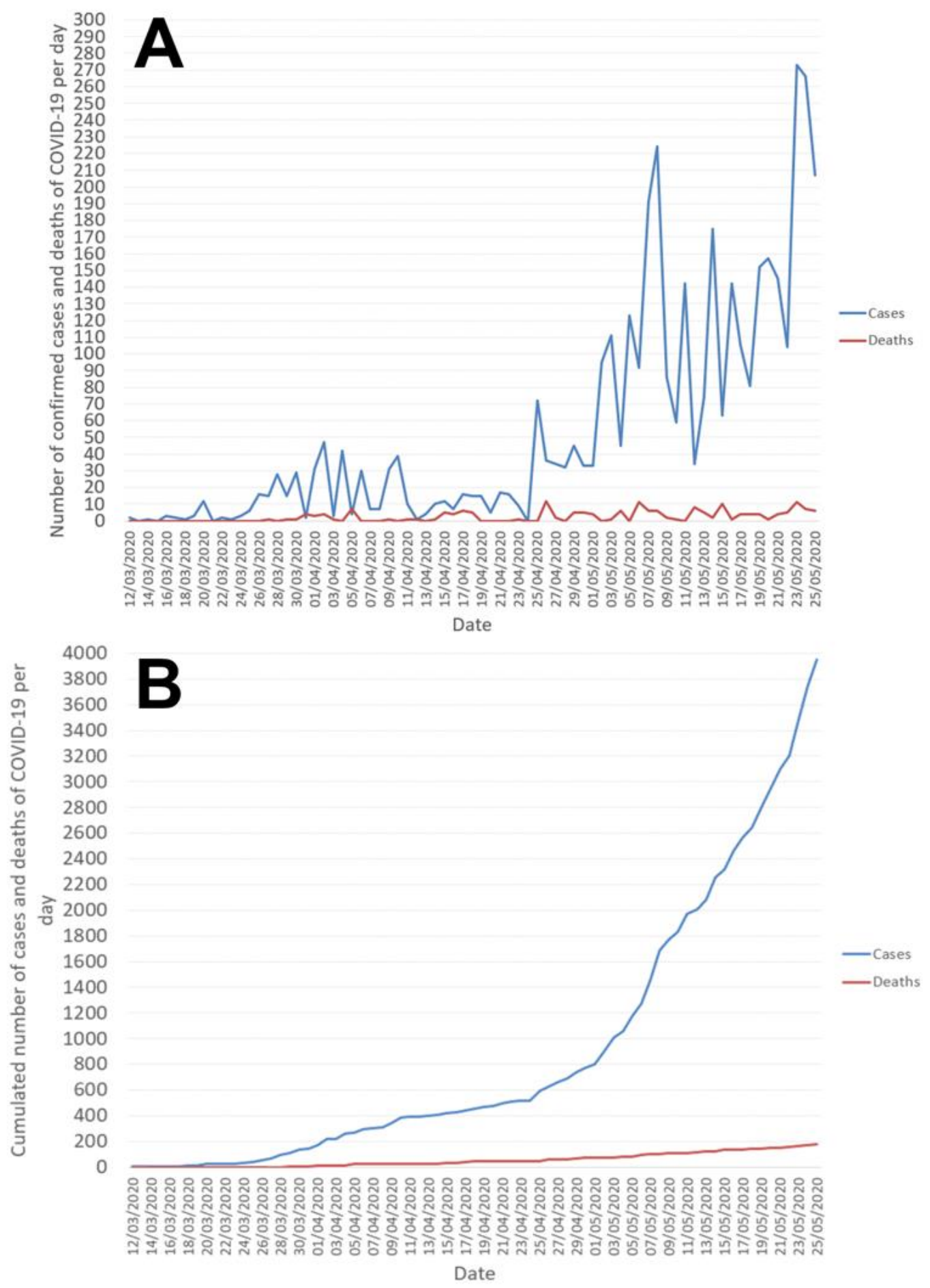
Figure 2. Tested applied to the population by departments. A. Total number of tests. B. Tests per 100,000 population.

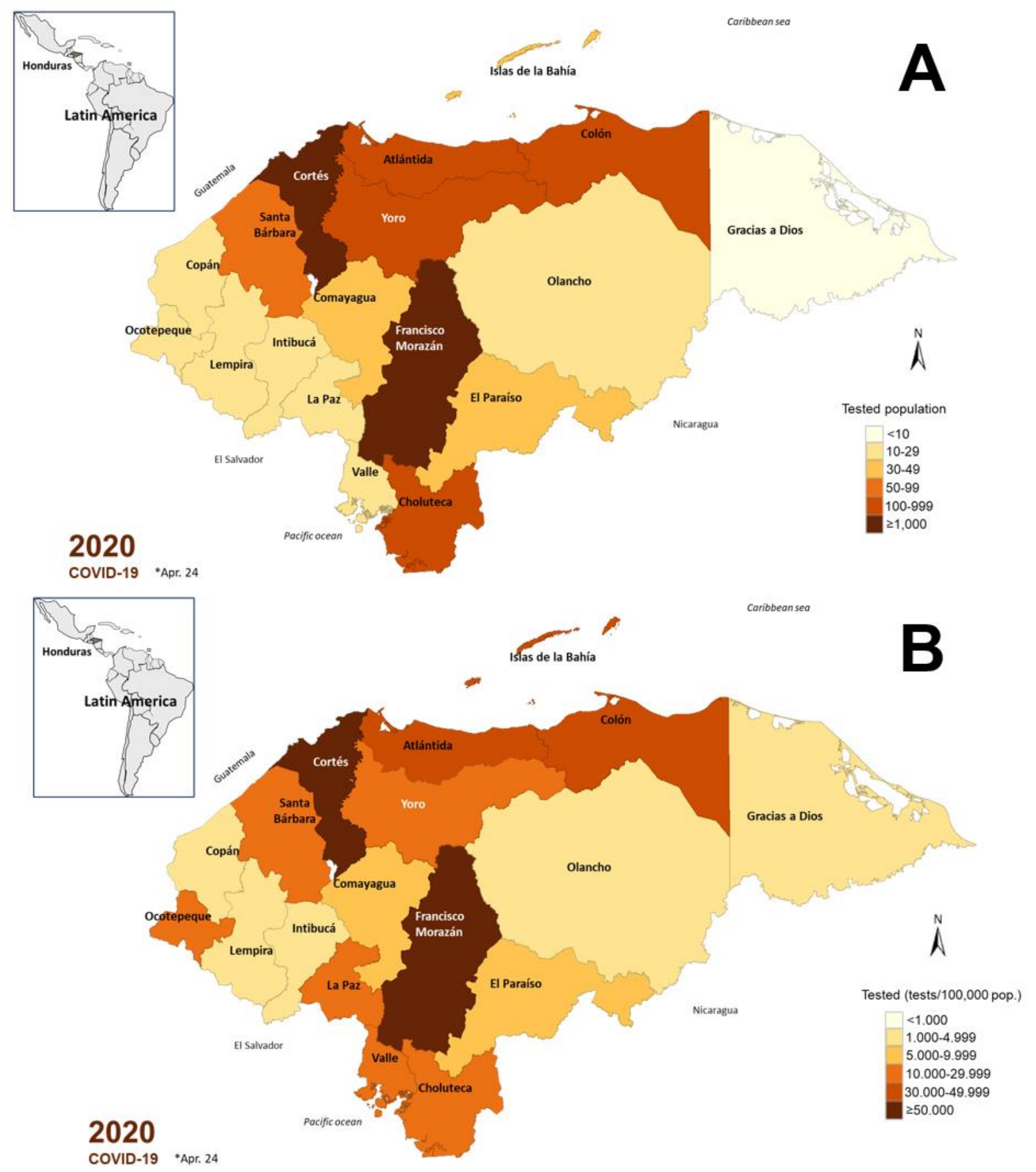


Figure 3. Tested applied per 100,000 population in the departments of Cortés and Francisco

Morazan.

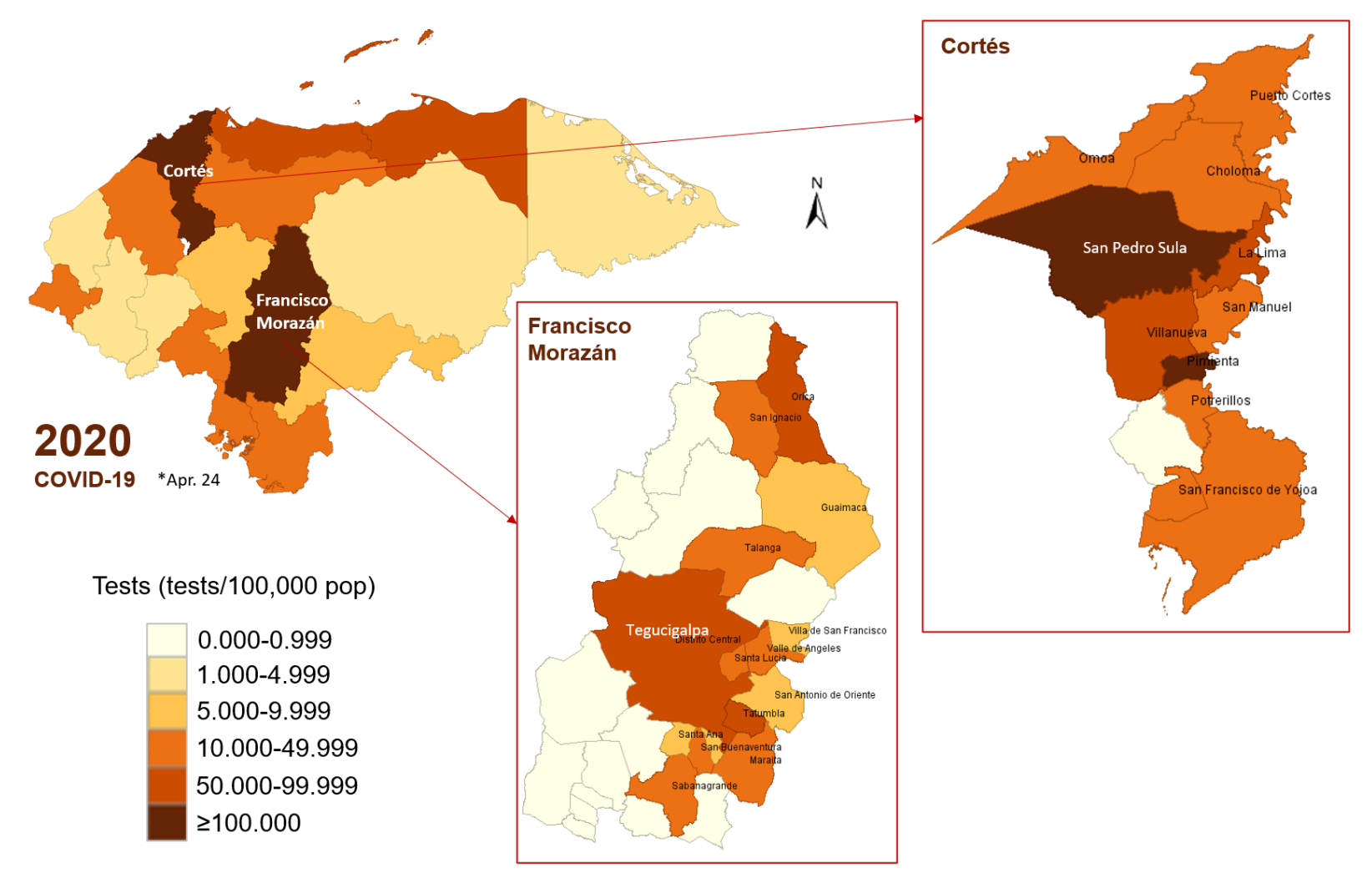


Figure 4. COVID-19 confirmed cases in Honduras by departments. A. Total number of cases.

B. Incidence rates (cases/100,000 pop.).

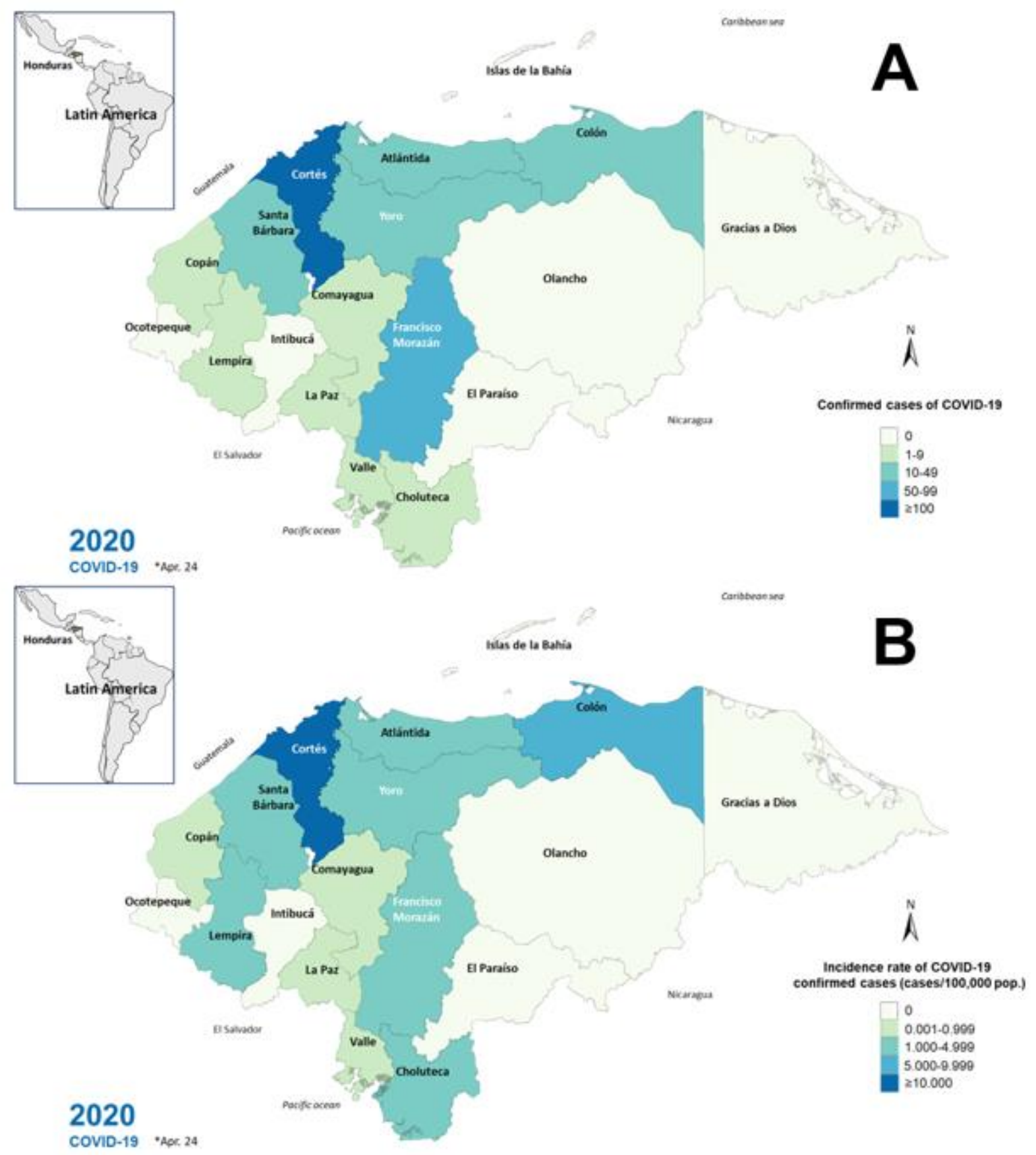


Figure 5. Tested applied to the population by municipalities. A. Total number of tests. B. Tests per 100,000 population.
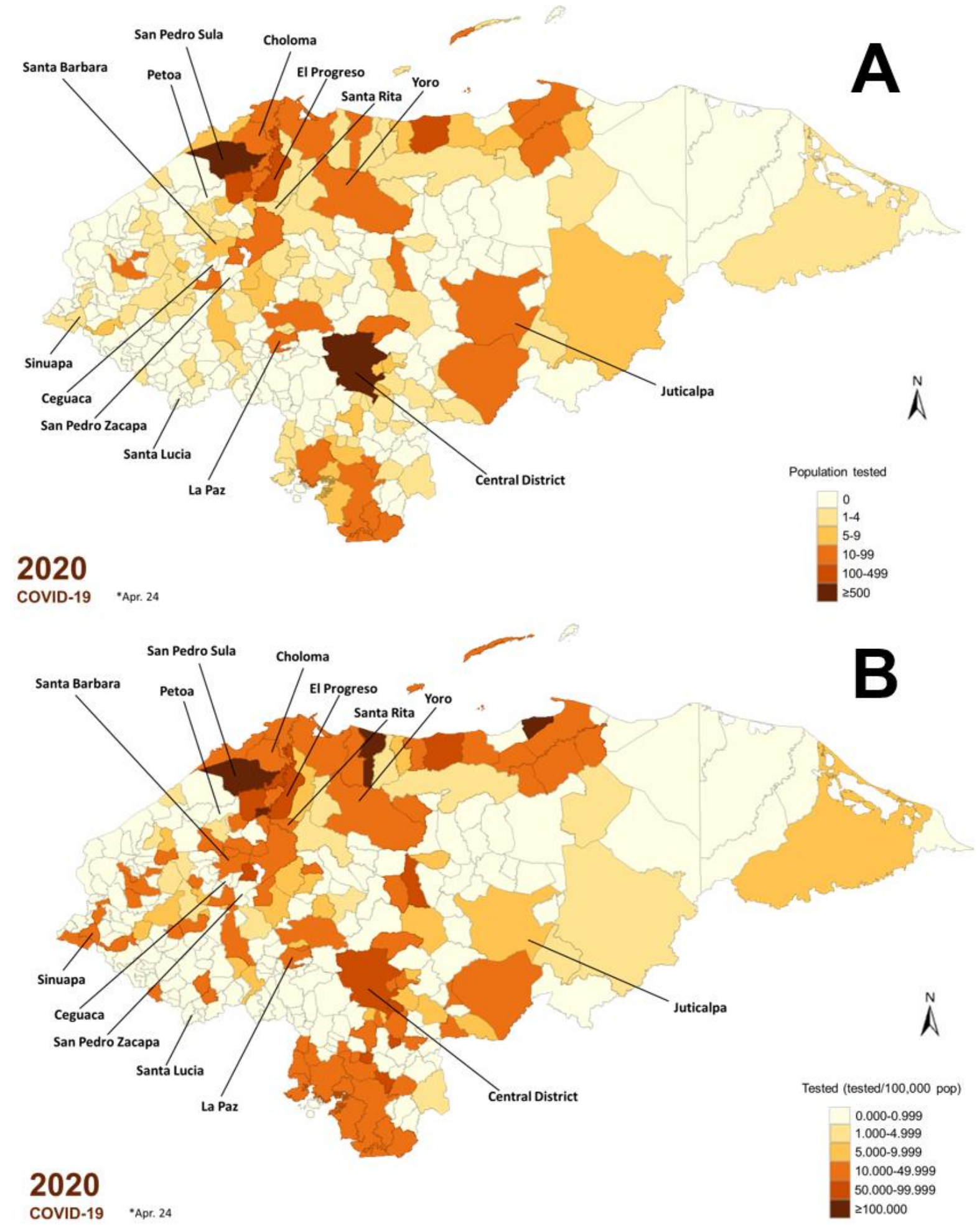
Figure 6. COVID-19 confirmed cases in Honduras by municipalities. A. Total number of cases. B. Incidence rates (cases/100,000 pop.).

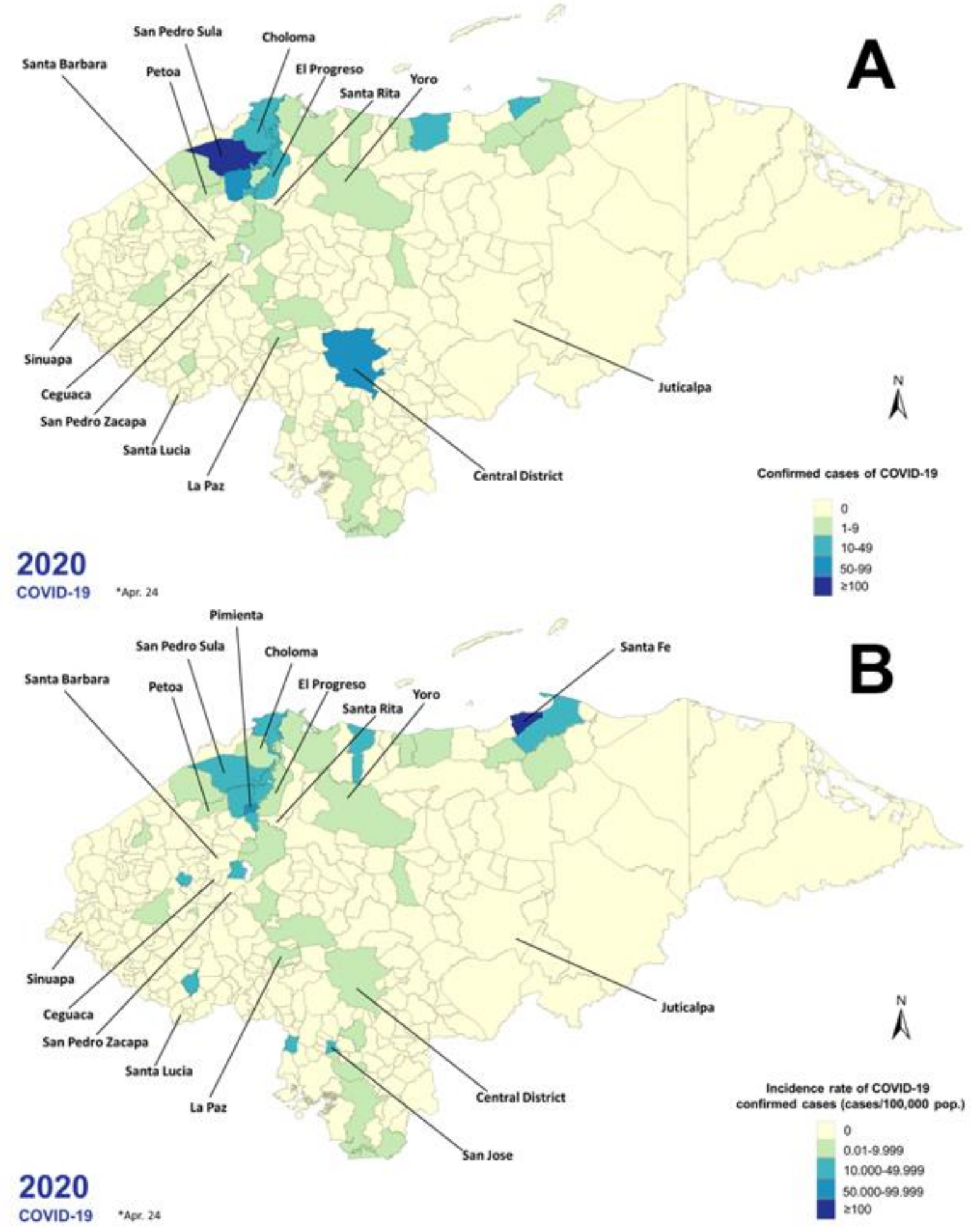

